\section{Pseudo food allergy}

SIR,-We wish to support the view expressed in Dr D J Pearson's leading article (25 January, $p$ 221) that many patients who present with the self diagnosis of food allergy do not have any form of food intolerance. It is also our experience that the multiple symptoms experienced by these patients are often due to the chronic hyperventilation syndrome. Although Lum ${ }^{\prime}$ fully described the clinical features of this condition, it is not widely recognised in the UK. Many patients with this syndrome have a serum potassium concentration at the lower end of, or even below, the normal range, and we have recently pointed out that the finding of moderate hypokalaemia without any obvious cause should always alert the clinician to the possibility of hyperventilation syndrome. ${ }^{2}$ It is an important diagnosis to make as the syndrome causes much morbidity and diagnostic confusion and often responds to treatment with breathing exercises accompanied by explanation and reassurance.

As Dr Pearson emphasises, true food allergy and intolerance do occur, ${ }^{3}$ and should always be considered seriously as effective treatment is often possible. We have recently analysed 12 consecutive patients who presented with intractable recurrent urticaria and angio-oedema (average duration nine years) who had not responded to treatment with antihistamines. Seven patients responded to an additive free diet excluding benzoates, artificial colours, and foods containing salicylates, two to yeast exclusion, one to wheat exclusion, and one to an antihouse dust mite regimen. One patient failed to respond to treatment. We therefore achieved success rate of 11 out of 12 in this small but difficult group of patients.

In contrast with Europe and America, facilities for allergy treatment in this country are poor, which is why so many patients are seeking help from non-medically qualified practitioners. We would therefore strongly support the suggestion that allergy facilities within the NHS should be expanded and that allergy should be viewed as a proper clinical subspecialty with a recognised training programme.

RONAL.D FINN Royal Liverpool Hospital A N BARTLETT Liverpool L7 8XP

1 Lum LC. Hyperventilation and anxiety states. $\mathcal{J} R$ Soc Med 1981;74:1-4.

2 Pearson MG, Quadiri MJ, Finn R. Hypokalaemia in the chronic hyperventilation syndrome. Br 7 Clin Pract (in press).

3 Royal College of Physicians, British Nutrition Foundation. Food intolerance and food aversion. $\mathcal{f} R$ Coll Physicians Lond 1984;18: 83-122.

\section{A boost for clinical research}

SIR,-You rightly draw attention (8 February, $p$ 362 and 416 ) to the proposals currently made to the Medical Research Council on the future of clinical research in this country. Sir Michael Stoker's committee on the Clinical Research Centre has made recommendations to the Medical Research Council which are far reaching, imaginative, and in the best interests of clinical research nationally. Its proposals that the Clinical Research Centre should be merged with the Royal Postgraduate Medica School and that basic science and clinical research should be brought together by moving the $\mathrm{Na}$ tional Institute for Medical Research to the same site are welcomed by many of us at the Clinical Research Centre.

When the centre was founded the Medical Research Council deliberately chose to site it alongside a district general hospital since they envisaged not only that the centre would fulfil a national role but also that the research workers would be brought into direct touch with everyday problems of disease as manifest in the community. In encouraging research into common diseases often neglected in traditional university medical departments the council was reflecting a view, widespread at that time, that university medicine was often obsessed or preoccupied with the esoteric and with high technology medicine. It has been an achievement of the Clinical Research Centre that the research workers and clinicians have had considerable success in applying the scientific method to disorders such as schizophrenia, obesity, alcohol abuse, the biology of blood vessels, infectious diseases, anaesthesia, diarrhoeal illnesses, allergy and disorders as banal as the common cold, for the Common Cold Unit at Salisbury is an important outstation of the centre.

The committee did not get everything right. It is not true that the beds at Northwick Park Hospital designated for research have not been fully used. The reason why research workers have used these beds in caring for patients from the local community has been to ensure that our clinical research staff should be brought into direct contact with the everyday problems of medicine, so that they keep their investigative feet firmly on the ground. At the same time they have had some success in the application of the techniques of molecular and cel biology to the study of human suffering.

The Royal Postgraduate Medical School at Hammersmith Hospital, on the other hand, has evolved an approach to medicine that is entirely different but complementary to that of the Clinical Research Centre at Northwick Park. Hammersmith is not a district general hospital in the ordinary sense of the word and no longer provides a comprehensive service for the community. Instead, through its successful research during the past half century, it has built up a formidable reputation for work in highly specialised areas of medicine-for example, open heart surgery, transplantation, the treatment of leukaemia, and imaging techniques as complex as magnetic resonance imaging. Much of this work is already supported by the Medical Research Council. In bringing together the excellence of the Clinical Research Centre's work in studies of disease in the context of a district general hospital and the high technölogy approach of Hammersmith, the council, together with the university and the health departments, will be creating a national centre for clinical research that will be unrivalled in Western Europe. That is, of course, provided that the interested parties can pull it off.

\section{CHRISTOPHER BOOTH}

Clinical Research Centre,

Northwick Park Hospital,

Harrow, Mddx HAl 3UJ

\section{Dialysis arthropathy: complication of long term treatment with haemodialysis}

SIR,-We read with interest the recent article by Dr E A Brown and others (18 January, p 163). For some time we have been struck by the existence of amyloid deposits in such dialysis arthropathies and published these observations last year. ${ }^{1-5} \mathrm{We}$ were followed by others, ${ }^{67}$ who drew the same conclusions: amyloid deposits are responsible for most of the arthropathies in patients receiving long term hemodialysis. More recently, we showed that there were histologically proved amyloid dialysis arthropathies in about $32 \%$ of our patients dialysed for more than seven years solely or mainly with poorly compatible cuprophane membranes $(n=31)$. No cases were seen in patients dialysed solely or mainly with polyacrylonitrile membranes during the same period $(n=11)$. It has recently been suggested that plasma $\beta_{2}$ microglobulin concentrations are higher in patients dialysed with cuprophane membranes than in those dialysed with polyacrylonitrile membranes. ${ }^{8}$ Therefore, $B_{2}$ microglobulin could represent a portion of these amyloid deposits still to be determined. We suggest that these factors should be systematically considered by those who are dealing with the pathogenesis of dialysis arthropathy.

J M VANDENBROUCKE J P HUAUX

C NAGANT DE DEuXChaISNES C VAN YPERSELE DE STRIHOU

Departments of Nephrology and Rheumatology,

St Luc University Hospital,

Louvain University in Brussels,

B-1200 Brussels

1 Huaux JP, Noël H, Bastien P, et al. Amylose articulaire, fracture du col fémoral et hémodialyse périodique chronique. Rev Rhum Mal Osteoartic 1985;52:179-82.

2 Huaux JP, Noël H, Malghem J, et al. Amyloidosis, a possible contributing factor to bone erosions and cysts in azotemic renal osteodysurophy on longterm hemodialysis. In: Norman AW, Schaefer K, Grigoleit HG, et al, eds. Vitamin D. A chemical, Schaefer K, Grigoleit HG, et al, eds. Vitamin D. A chemical,
biochemical and clinical update. Berlin: Walter de Gruyter, biochemical and

3 Huaux JP, Noël H, Malghem J, et al. Erosive azotemic osteoarthropathy: possible role of amyloidosis. Arthritis Rheum 1985;28: 1075-6.

4 Vandenbroucke JM, Huaux JP, Guillaume T, et al. Capsulo synovial and bone amyloidosis: complication of long-term haemodialyis (HD). Kidney Int 1985;28:360.

5 Vandenbroucke JM, Huaux JP, Guillaume T, et al. Amyloïdose capsulo-synoviale une complication à long terme de l'hémocapsulo-synoviale une complicati
dialyse. Néphrologie 1985;6:94.

6 Bardin T, Kuntz D, Zingraff J, et al. Synovial amyloidosis in patients undergoing long-term hemodialysis. Arthritis Rheum 1985;28:1052.

Munoz-Gomez J, Bergada-Barado E, Gomez-Perez R, et al. Amyloid arthropathy in patients undergoing periodical haemodialysis for chronic renal failure: a new complication. Ann Rheum Dis 1985;44:729-33.

8 Kostic S, Djordjevic V, Lecic N. Serum B2-microglobulin in patients on maintenance hemodialysis. The effect of dialysis membrane. Kidney Int 1985;28:338.

How do you resuscitate someone with a spinal cord injury?

SIR,-Dr David Cargill (8 February, p 408) highlights some confusion generated by the recent correspondence on the management of the unconscious spinal injury victim at the scene of the accident (30 November, p 1558; 11 January, p 138).

The aims and objectives of the recovery position have been agreed internationally (instructors' manual for the league of Red Cross Societies and the World Federation of Societies of Anaesthesiologists). The position-elsewhere known as the coma position or the lateral safety positionshould allow the airway to be kept free by preventing the base of the tongue from falling backwards and obstructing the throat, as would happen with the casualty left on his back.

"1 The procedure should minimise the movement of the casualty. This is particularly important if the casualty is the victim of an accident for movement of the injured part, especially the head and neck [my italics] can seriously aggravate the injury.

2 The casualty's head, neck and trunk should be kept in a straight line as he is being moved and once he is in ... position. Once again this is of particular importance in an injured casualty for twisting of the head or neck can be very dangerous if the neck has been injured.

3 The position should permit gravity drainage of liquid foreign material from the casualty's mouth.

4 The position should be stable, that is the casualty should not roll or topple into another position once he has been placed." 